30

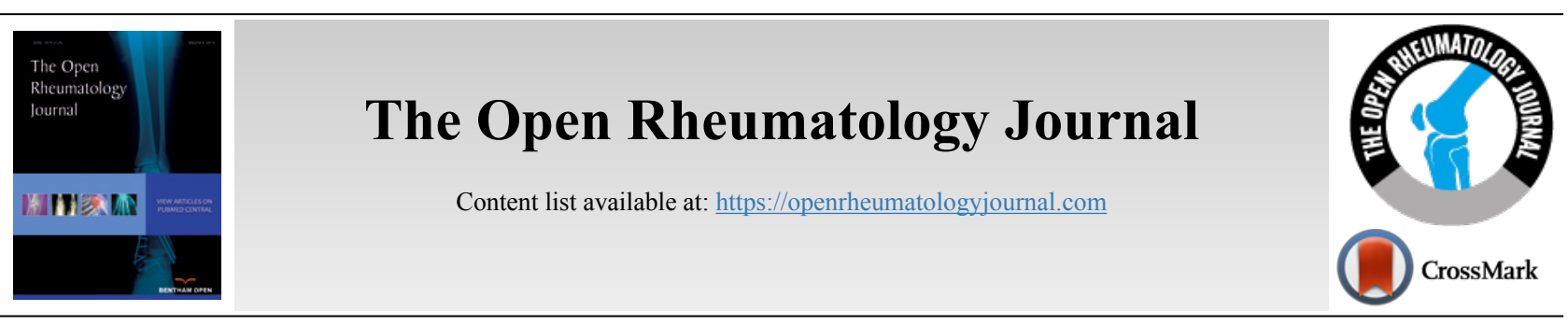

RESEARCH ARTICLE

\title{
Cross-Cultural Adaptation and Psychometric Properties of Osteoporosis Knowledge Tool-Arabic Version Among Iraqi Population
}

Shaymaa Abdalwahed Abdulameer and Mohanad Naji Sahib*

Faculty of Pharmacy, Al-Rafidain University College, Palestine Street, 10052, Baghdad, Iraq

\begin{abstract}
:
Background:

Osteoporosis is a major public health problem as the majority of people are not aware of the disease until the complications occur.

Objective:

The aims of this study were to validate Osteoporosis Knowledge Tool (OKT-A) Arabic version and to assess the osteoporosis knowledge among Iraqi general population.

Methods:

A descriptive, cross-sectional study was carried out in the city of Baghdad with a random cluster sampling method from the community. Forward-backward-forward translation method was used to translate the OKT questionnaire from English into Arabic language. The psychometric assessment process includes: face validity, reliability (Cronbach's alpha and test-retest), item difficulty index, point biserial correlation and discriminatory power.

Results:

The results showed good face validity. The Cronbach's alpha and Pearson correlation coefficient of the test re-test reliability were 0.775 and 0.412 respectively. Item difficulty index, point biserial correlation ranges and discriminatory power were 0.105 to $0.852,0.105$ to 0.445 and 0.933 , respectively. These results demonstrated that OKT-A was a reliable and stable tool. The results showed low OKT-A scores $11.50 \pm 3.958$ Furthermore, the OKT-A scores and its subscales were less than $50 \%$. In addition, there were significant differences between the following independent variables in relation to total OKT-A scores: educational level, do you have osteoporosis or ever heard about osteoporosis. Moreover, there was a significant association between ever heard about osteoporosis groups and the OKT-A knowledge levels.

\section{Conclusion:}

This study showed good validity and reliability of OKT-A tool among Arabic general population. In addition, the results showed an urgent need for implementing an educational programme and should be a public health practice to increase the knowledge toward osteoporosis and its related risk factor.
\end{abstract}

Keywords: Arabic, Knowledge, Osteoporosis, Validation, Psychometric properties, BMD.

Article History Received: January 18, 2019

Revised: February 08, 2019

Accepted: March 08, 2019

\section{INTRODUCTION}

Osteoporosis (OP) is a silent painless metabolic process that leads to the increase in bone fragility, susceptibility to fractures and premature death rate [1 - 4]. OP is characterised by decrease in Bone Mineral Density (BMD), which is due to the microarchitectural deterioration of bone tissue [5]. As it

"Address correspondence to the Faculty of Pharmacy, Al-Rafidain University College, Palestine Street, 10052, Baghdad, Iraq; Tel:00964-07723607555;

E-mail: mohanad_pharm@yahoo.com affects both sex, it's a major public health problem as more people are not aware about it until complications occur [6 - 8]. In addition, OP leads to a decrease in the quality of life as a result of severe back pain, loss of independence, costly rehabilitation and excessive health care [2,9].

As with other chronic disease, prevention of OP is critically important. Lifestyle modification is the key component in this prevention process to increase bone mass density. Managing modifiable risk factors like regular weight- 
bearing exercise, increase calcium and vitamin D intake, stop smoking and alcohol intake are the cornerstone in preventing OP development [10,11].

Strategies focused on gaining information toward osteoporosis are important for promoting osteoporosis preventing behaviour for high-risk populations and preserving lifelong bone health [12 - 17]. A review article by Werner P. discusses the utility of several tools that used to assess knowledge toward osteoporosis [18]. Though, the Osteoporosis Knowledge Test (OKT, 24 items) is the most reliable and widely used tool that had been successfully translated and validated in different communities, there is paucity in literatures regarding its use for Arabic cultures. Moreover, the only Arabic tool that was found in the literatures was Osteoporosis Knowledge Assessment Tool (OKAT) which is 32 items [19 - 21]. This makes OKT questionnaire an easy and short to answer and valuable to be assessed. Moreover, it is surprising that approximately $1 \%$ of the global research output regarding OP were published from Arab countries [22]. Accordingly, this topic is vital to be evaluated for improving OP prevention strategies and behaviour. Therefore, the aims of this study were to assess cross-cultural adaptation and psychometric properties of OKT Arabic version and to evaluate the osteoporosis knowledge among Iraqi general population.

\section{MATERIALS AND METHODS}

\subsection{Participants and Study Design}

A descriptive, cross-sectional study from the community was conducted from November 2016 to February 2017 in Baghdad capital, Iraq. Random cluster sampling method was used to select three areas from two large district areas named Al-Rusafa (six districts; east of the Tigris) and Al-Kharkh (four districts; west of the Tigris) of Baghdad. Equal number of participants from each area was recruited through systemic random sampling method. Community pharmacies where the undergraduate students undertake their training were used as a place to invite the participants in each area. The inclusion criteria for participants were: more than 18 years, no cognitive impairment, able to write and read in Arabic. Though structured interview included the administration of sociodemographic data and the translated OKT-Arabic version (OKT-A), each participant was interviewed individually by the researchers or trained $5^{\text {th }}$ year undergraduate student after written informed consent.

\subsection{Sample Size}

A recommendation suggested that at least 5 subjects per item are needed to evaluate the validity and reliability of a questionnaire [23]. The original OKT consist of 24 questions; therefore 120 participants were needed for the purpose of validation. Doubling the sample size, with an additional $30 \%$ as drop out was considered necessary for the study to overcome erroneous results. Only 400 participants were accepted to be involved in this study, however, 75 of them were ineligible due to incomplete responses. Therefore, only 325 participants were selected for this study ( 25 participants for pilot study and 300 for the final study analysis). Twenty five participants from the sample population were randomly selected for test- retest within 1-2 weeks according to the participant's convenience.

\subsection{Instruments and Measurements}

All participants completed the structured questionnaires including OKT-A. The original OKT is in English language and designed to measure osteoporosis knowledge with 24 multiple-choice items regarding risk factors and its prevention. It is divided into two parts: OKT-exercise subscale and OKTcalcium subscale. From 0 to 24 is the possible score range and the highest value indicate the highest level of knowledge score [24]. A cut-off point [14] was used to categorize the osteoporosis knowledge scores into two levels: low and high OKT-A [25].

\subsection{Instrument Translation}

Permission to use the OKT was obtained from the author of the original instrument. Forward-backward-forward translation method was used to translate the questionnaire from English into Arabic according to translation international guidelines including forward translation, reconciliation, reverse translation, debriefing [26 - 29]. The translation process was undertaken by two independent expert translators in Iraq . Thereafter, the researchers and an expert panel (eight clinical pharmacists) reviewed the Arabic version for reconciliation. Then, the reconciled version was again translated by two different translators. Then, repeated discussions between the researchers, the expert panel and the translators were undertaken to resolve any inconsistencies and harmonise the final version. Finally, twenty five participants from the same study demographic areas were recruited for a pilot study and the questionnaire was modified according to their feedback to be a face valid tool (Face validation process). The pilot study results were excluded from the results of the final study analysis and sample size.

\subsection{Reliability and Validation}

\subsubsection{Reliability}

Reliability with a minimum acceptable criterion above 0.5 was applied to measure the consistency of a measurement item [30]. The internal consistency was evaluated using Cronbach's alpha and corrected item total correlations between the scales and their corresponding items (correlation of $<0.20$ is considered poor). Pearson's correlation coefficient was used to evaluate test-retest reliability [23].

\subsubsection{Item Difficulty Index}

The item difficulty index $(\mathrm{P})$ is a measure of difficulty to answer the question. It is the ratio between the numbers of respondents answering the item correctly to the total number of responses. The $(\mathrm{P})$ value is a range between 0 (meaning no one can answer the question correctly) to 1 (meaning everyone can answer this question correctly). The most acceptable values are between 0.3 and 0.7 . An items with values more than 0.75 is considered poor, i.e., these items are answered correctly more frequently [31]. 


\subsubsection{Point Biserial Correlation and Discriminatory Power}

The point biserial correlation is the reliability index for each item and refers to an item-total correlation. A correlation of $<0.20$ is considered poor [23]. On the other hand, discriminatory power indicates how broadly the total scores of a sample are distributed over the possible range. It can be measured using Ferguson's sigma and the item is consider discriminant if the value is above 0.9 [32].

\section{STATISTICAL ANALYSIS}

Predictive Analytics Software (PASW) version 19.0 was used to analyse data in this study. Descriptive statistics, percentages and frequencies were used as needed. The significance level was set at a $P$ value less than 0.05 . The chi square $(\chi 2)$ test was employed for categorical variables while for continuous data, Mann-Whitney U and Kruskal-Wallis tests were used to evaluate the differences between the groups when required. The statistical analysis of the validation and reliability processes included (Cronbach's alpha and test-retest) and item analysis.

\section{RESULTS}

\subsection{Socio-Demographic}

The average age of the participants was $41.82 \pm 12.452$ years with a range from 18 to 87 years. The majority of respondents were female (54\%). Nearly $79 \%$ of the patients had educational level beyond secondary school (more than 12 years). More than half of the participants were married (77\%) and had monthly income more than 500,000 thousand Iraq dinner (IQD) (62\%; IQD; 1 US dollar is equivalent to 1,200 IQD). The majority of respondents had heard about osteoporosis (93\%). The most common sources of information about OP as follows: internet (34\%), doctor (31.7\%), family and friends (17.3\%). A smaller proportion of respondents had heard about osteoporosis from the pharmacist $(6.7 \%)$, television (10.7\%), social media (11.7\%), magazine (5.3\%) and medical advertisement (5\%).

By employing the recommended scoring method, the mean score $(\mathrm{M} \pm \mathrm{SD})$ of the OKT-A was $11.50 \pm 3.958$, which was considered a low score. Table $\mathbf{1}$ shows the demographic data results and the distribution of the two levels of osteoporosis knowledge. Only $31.70 \%$ of the study population was found to have high OKT-A level. The results showed significant difference between the following independent variables in relation to total OKT-A scores: educational level $(P<0.005)$, Do you have osteoporosis $(P<0.005)$ and ever heard about osteoporosis $(P<0.001)$. In addition, there was a significant association between ever heard about osteoporosis groups and the OKT-A knowledge levels $(P<0.01)$ (Table 1).

Table 2 shows the correct answer percentage of OKT-A and its two subscales and Table $\mathbf{3}$ shows the percentage of correct response and incorrect response of each question of
OKT-A among sample population. The results showed that the OKT-A scores and its subscales were less than $50 \%$. The lowest value was within the OP knowledge toward risk factors. Less than $30 \%$ correct answers were found within the questions 3 (Having big bones), 4 (Eating a diet high in dark green leafy vegetables) and 7 (Having ovaries surgically removed). In addition, the lowest values in OKT-A exercise subscale were questions: 14 (30.30\%, Exercise makes bones strong, but it must be hard enough to make breathing) and $16(27.30 \%$, Which of the following exercise is the best way to reduce a person's chance of getting osteoporosis). Moreover, the lowest values in OKT-A calcium subscale were questions: 21 $(32.30 \%$, Which of these is a good source of calcium) and 22 $(9.70 \%$, Which of the following is the recommended amount of calcium intake for an adult).

\subsection{Validation and Reliability}

The face validity of the OKT-A questionnaire was guaranteed and showed good readability as per feedback from of the eight professionals, the pilot study and the extensive translation method. Then, the tool was ready for testing the main objectives. Regarding item analysis for OKT-A, the item difficulty index for most items were between 0.105 and 0.852 , which is satisfactory (Table 4). Only three items (Item 15, 17 and 20) scored above 0.75 which indicated that most of the subjects answered these questions correctly, and only one item (Item 22) had a low difficulty index below 0.2. However, these four items were retained as they reflected basic knowledge regarding osteoporosis. The corrected item-total correlation (Point Biserial Correlation) values ranged from 0.105 to 0.445 (Table 4).

Although only one item (item 22) showed corrected itemtotal correlation value of less than 0.20 , all items appeared to be suitable for retention depending on the meaningfulness of the items. Ferguson's sigma for the questionnaire was 0.933 , which is considered prefect.

For the reliability, the Cronbach's alpha test of internal consistency was 0.775 for the twenty four items in OKT-A, and it's within the recommended acceptable result for reliability [30]. The test-retest reliability of 24 items OKT-A indicated an excellent reliability and stability of the instrument with Pearson correlation coefficient of $0.412(P<0.05)$. An initial Cronbach's alpha result for the OKT-A test-retest group was 0.474 , and after 1 to 2 weeks, it was 0.727 . These results demonstrated that OKT-A was reliable and stable.

\section{DISCUSSION}

To reduce the risk of future bone fractures, osteoporosis prevention by the mean of educational programme is the most effective way. Nonetheless, before any educational programme to be implemented, the knowledge must be assessed so that the programme could be tailored according to the required need for the population. Hence, this is the first study that translates and 
validated comprehensively the OKT to Arabic language. The reliability of the OKT-A, which is the consistency of a measurement item, was good with an acceptable overall Cronbach's alpha [30]. This result was comparable to the original OKT tool and the translated Malaysian and Persian OKT $[25,33,34]$. The test-retest reliability Cronbach's alpha value after 1-2 weeks was higher than the initial value indicating that the respondents may be more aware about OP and this could be used in longitudinal or cohort studies to measure the change in knowledge level. In addition, the difficulty indexes which assess the difficulty of the items to be answered correctly were within the acceptable level [31]. Moreover, point biserial correlation and Ferguson's sigma values which are an item-total correlation and discriminatory power, respectively, were within the acceptable range and indicated that the tool is reliable and discriminating $[23,32]$.

Table 1. Participants demographic characteristics.

\begin{tabular}{|c|c|c|c|}
\hline Characteristics & $\begin{array}{c}\text { Low Knowledge } \\
(\mathrm{N}=\mathbf{2 0 5})\end{array}$ & $\begin{array}{c}\text { High Knowledge } \\
(\mathrm{N}=95)\end{array}$ & Total Samples $(\mathrm{N}=300)$ \\
\hline 24 item OKT-A score & $9.40 \pm 2.720$ & $16.03 \pm 1.859$ & $11.50 \pm 3.958$ \\
\hline OKT-A exercise & $5.66 \pm 2.190$ & $10.85 \pm 1.902$ & $7.30 \pm 3.204$ \\
\hline OKT-A calcium & $6.63 \pm 2.196$ & $11.13 \pm 1.715$ & $8.05 \pm 2.934$ \\
\hline \multicolumn{4}{|l|}{ Age } \\
\hline$\leq 44$ & 56.6 & 66.3 & 59.7 \\
\hline$\geq 45$ & 43.4 & 33.7 & 40.3 \\
\hline \multicolumn{4}{|l|}{ Gender } \\
\hline Male & 47.3 & 43.2 & 46 \\
\hline Female & 52.7 & 56.8 & 54 \\
\hline \multicolumn{4}{|l|}{ Educational levels $^{\text {a }}$} \\
\hline$<12$ years & 23.4 & 15.8 & 21 \\
\hline$\geq 12$ years & 76.6 & 84.2 & 79 \\
\hline \multicolumn{4}{|l|}{ Marital status } \\
\hline Single & 22 & 25.3 & 23 \\
\hline Married & 78 & 74.7 & 77 \\
\hline \multicolumn{4}{|l|}{ Employment status } \\
\hline Working & 82.9 & 86.3 & 84 \\
\hline Unemployed & 17.1 & 13.7 & 16 \\
\hline \multicolumn{4}{|l|}{ Monthly income (IQD) } \\
\hline$\leq 500,000$ & 38 & 37.9 & 38 \\
\hline$>500,000$ & 62 & 62.1 & 62 \\
\hline \multicolumn{4}{|l|}{ Living place } \\
\hline Rural & 22.9 & 20 & 22 \\
\hline Urban & 77.1 & 80 & 78 \\
\hline \multicolumn{4}{|c|}{ Family history of osteoporosis } \\
\hline No & 73.2 & 71.6 & 72.7 \\
\hline Yes & 26.8 & 28.4 & 27.3 \\
\hline \multicolumn{4}{|l|}{ Family history of fracture } \\
\hline No & 57.6 & 62.1 & 59 \\
\hline Yes & 42.4 & 37.9 & 41 \\
\hline \multicolumn{4}{|c|}{ Do you have osteoporosis a } \\
\hline No & 87.8 & 92.6 & 89.3 \\
\hline Yes & 12.2 & 7.4 & 10.7 \\
\hline \multicolumn{4}{|c|}{ Ever heard about osteoporosis ${ }^{\text {b,c }}$} \\
\hline No & 9.8 & 1.1 & 7 \\
\hline Yes & 90.2 & 98.9 & 93 \\
\hline \multicolumn{4}{|c|}{ Osteoporosis diagnosis or screening } \\
\hline No diagnosis before & 81.5 & 83.2 & 82 \\
\hline Yes diagnosis & 18.5 & 16.8 & 18 \\
\hline \multicolumn{4}{|l|}{ Smoking habit } \\
\hline Not smoking & 80 & 77.9 & 79.3 \\
\hline Smoking & 20 & 22.1 & 20.7 \\
\hline Alcohol habit & & & \\
\hline
\end{tabular}


(Table 1) contd.....

\begin{tabular}{|c|c|c|c|}
\hline Characteristics & $\begin{array}{c}\text { Low Knowledge } \\
(\mathbf{N}=\mathbf{2 0 5})\end{array}$ & $\begin{array}{c}\text { High Knowledge } \\
(\mathbf{N}=\mathbf{9 5})\end{array}$ & 100 \\
\hline Non alcoholic & 99 & 0 & 99.3 \\
\hline Alcoholic & 1 & 0.7 & 0.3 \\
\hline
\end{tabular}

Data expressed as mean \pm standard deviation $\left(\mathrm{M} \pm \mathrm{SD}\right.$ ) or frequency (percentage, \%); IQD: Iraq dinner (1 US dollar is equivalent to 1200 IQD; ${ }^{\text {a }}$ significant difference $P<0.05 ;{ }^{\mathrm{b}}$ significant difference $P<0.001$. $^{\mathrm{c}}$ significant association between groups $P<0.01$.

Table 2. Description of osteoporosis knowledge test-Arabic version ( $\mathbf{N}=\mathbf{3 0 0})$.

\begin{tabular}{|c|c|c|c|}
\hline Variable & Mean \pm Standard Deviation (Median) & Potential Range & Correct \% \\
\hline Osteoporosis Knowledge Test Arabic version (OKT-A) & $11.50 \pm 3.958(11)$ & $0-24$ & $47.93 \%$ \\
\hline Osteoporosis knowledge to risk factors & $3.85 \pm 2.10(4)$ & $1-9$ & $42.81 \%$ \\
\hline Osteoporosis Knowledge Test Exercise subscale (OKT-A exercise) & $7.30 \pm 3.204(7)$ & $0-16^{*}$ & $45.64 \%$ \\
\hline Osteoporosis Knowledge Test-Calcium subscale (OKT-A calcium) & $8.05 \pm 2.934(8)$ & $0-17 *$ & $47.36 \%$ \\
\hline
\end{tabular}

*Sum of the potential range for the Exercise subscale and Calcium intake subscale was larger than total potential range because the two subscales shared nine common questions (1-9).

Table 3. Percentage of correct and incorrect responses among sample population $(\mathbf{N}=\mathbf{3 0 0})$.

\begin{tabular}{|c|c|c|}
\hline Question Number & Correct Response (\%) & Incorrect Response (\%) \\
\hline Question 1 & 45.7 & 54.3 \\
\hline Question 2 & 40 & 60 \\
\hline Question 3 & 23.3 & 76.7 \\
\hline Question 4 & 25 & 75 \\
\hline Question 5 & 48.3 & 51.7 \\
\hline Question 6 & 58.7 & 41.3 \\
\hline Question 7 & 27.3 & 72.7 \\
\hline Question 8 & 48 & 52 \\
\hline Question 9 & 69 & 31 \\
\hline Question 10 & 60.7 & 39.3 \\
\hline Question 11 & 53.3 & 46.7 \\
\hline Question 12 & 45.7 & 54.3 \\
\hline Question 13 & 53.7 & 46.3 \\
\hline Question 14 & 30.3 & 69.7 \\
\hline Question 15 & 74 & 26 \\
\hline Question 16 & 27.3 & 72.7 \\
\hline Question 17 & 86.3 & 13.7 \\
\hline Question 18 & 65.7 & 34.3 \\
\hline Question 19 & 58.3 & 41.7 \\
\hline Question 20 & 81.3 & 18.7 \\
\hline Question 21 & 32.3 & 67.7 \\
\hline Question 22 & 9.7 & 90.3 \\
\hline Question 23 & 36 & 64 \\
\hline Question 24 & 50.3 & 49.7 \\
\hline
\end{tabular}

The results showed low correct answer frequencies for all dimension with low overall knowledge score. Similar results using OKT tool showed low level of knowledge regarding OP $[12,15,35,36]$. In addition, other studies in Arabic population using Osteoporosis Knowledge Assessment Tool (OKAT) showed similar results [20,37]. Preventive measurements are effective in controlling OP, unless the persons are familiar with them. Previous report showed that low calcium rich food intake and lack of exercise was associated with low OP knowledge level [13]. The results showed that the respondents were unable to identify that having big bones and having ovaries surgically removed as risk factors to get OP. Similar results showed that low identification level to the risk factors of OP were also reported $[13,35]$. Moreover, the respondents were unable to identify the recommended daily dose of calcium and the alternate food rich in calcium beside cheese and yogurt. Beside this, the respondents knew that exercising on a regular base, briskwalking and jogging or running can prevent OP. However, 
Table 4. Psychometric properties of the osteoporosis knowledge test-Arabic version (OKT-A) by item analysis $(\mathrm{N}=300)$.

\begin{tabular}{|c|c|c|c|}
\hline $\begin{array}{l}\text { Question } \\
\text { Number }\end{array}$ & $\begin{array}{l}\text { Difficulty } \\
\text { Index }\end{array}$ & $\begin{array}{l}\text { Point Biserial } \\
\text { Correlation* }\end{array}$ & $\begin{array}{l}\text { Cronbach's alpha } \\
\text { if item deleted }\end{array}$ \\
\hline Question 1 & 0.463 & 0.345 & 0.766 \\
\hline Question 2 & 0.383 & 0.326 & 0.767 \\
\hline Question 3 & 0.228 & 0.261 & 0.770 \\
\hline Question 4 & 0.247 & 0.281 & 0.769 \\
\hline Question 5 & 0.444 & 0.244 & 0.772 \\
\hline Question 6 & 0.574 & 0.297 & 0.769 \\
\hline Question 7 & 0.272 & 0.362 & 0.765 \\
\hline Question 8 & 0.475 & 0.402 & 0.762 \\
\hline Question 9 & 0.685 & 0.333 & 0.768 \\
\hline Question 10 & 0.642 & 0.432 & 0.762 \\
\hline Question 11 & 0.537 & 0.445 & 0.758 \\
\hline Question 12 & 0.463 & 0.354 & 0.766 \\
\hline Question 13 & 0.531 & 0.373 & 0.764 \\
\hline Question 14 & 0.333 & 0.297 & 0.769 \\
\hline Question 15 & 0.772 & 0.413 & 0.761 \\
\hline Question 16 & 0.284 & 0.289 & 0.769 \\
\hline Question 17 & 0.852 & 0.232 & 0.772 \\
\hline Question 18 & 0.654 & 0.105 & 0.776 \\
\hline Question 19 & 0.685 & 0.230 & 0.772 \\
\hline Question 20 & 0.809 & 0.282 & 0.769 \\
\hline Question 21 & 0.272 & 0.275 & 0.770 \\
\hline Question 22 & 0.105 & 0.404 & 0.762 \\
\hline Question 23 & 0.309 & 0.241 & 0.771 \\
\hline Question 24 & 0.543 & 0.261 & 0.770 \\
\hline
\end{tabular}

* Give corrected item-total correlation

they did not know how many days a week, the intensity of the exercise required and the alternate type of exercise like Aerobic dancing to prevent OP. Previous reports showed related results [38 - 41].

This study showed that $68.30 \%$ of the respondents had insufficient OP knowledge despite high awareness of the sample population regarding OP $(93 \%$ heard about OP). This may be due to incorrect or inadequate information regarding OP had been gained. This result is consistent with the previous reports. Ribeiro et al. found that women possess limited knowledge and do not take adequate measures to prevent osteoporosis when they are receiving inadequate information about the disease [42]. In addition, Turkish study showed that although $60 \%$ of the respondents had heard about OP, only $44.9 \%$ of them could correctly define it [39]. Moreover, Taylor et al. showed that education and practicing to prevent OP by general practitioners in London was consider inadequate, however, their awareness of the importance of preventing OP was adequate [43]. Furthermore, Werner P. showed a serious deficit in OP knowledge for both general population and healthcare professionals [18]. Additionally, the results showed that only $6.7 \%$ of the sample population had heard about OP form pharmacists which indicated that the counselling and prevention strategies of the pharmacists were questionable. However, this was not measured in this study, but three recent studies showed that this result may be due to the fact that the pharmacists were either reactive than proactive regarding OP counselling or had low knowledge regarding OP prevention strategies [44 - 46]. Therefore, an educational program with reliable information is an urgent necessity to increase the awareness to prevent OP. In addition, using the OKT-A would be a useful tool in general practice to identify the population with low OP knowledge level.

Furthermore, it appears that the total OKT-A score was enhanced when the educational level increases ( $\geq 12$ years). This finding was comparable with the other report [47, 48, 41]. In general, it is obvious that osteoporotic patients are more likely to have more information about OP. However, in this study, the total OKT-A and OKT-A exercise subscale were decreased significantly, if the respondents have OP. This indicated that the respondents were still unaware about the suitable exercise to prevent osteoporosis. Similar results showed intervention directed to the patients and their physicians will increase the patients' OP knowledge [49].

As previously mentioned, the respondents did not identify the alternate source of calcium or type of exercise due to their deficient knowledge. In Iraq, the culture does not accept someone running or cycling in the street and this applies particularly for women. In addition, the long hot summer weather does not let the person do regular exercise out door. Hence, the space and time are obstacles. Furthermore, adopting a healthier lifestyle is an obstacle due to the unavailability of 
alternative foods in the markets and/or they are more expensive $[50,51]$. Previous reports showed that high calcium intake levels were associated with a high motivation to health and OP knowledge [35, 52 - 54]. Therefore, those respondents could change their behaviours by increasing their knowledge and a consequence increase health motivation and practice. Consequently, the results recall the previous conclusions that the knowledge as a single measure is insufficient but can be a preparation phase to start the preventive healthy behaviours $[55,56]$. This means that sample population could cop the barriers in future if they had good knowledge toward OP.

As with the other cross sectional study, the results cannot be generalised for all population. However, the full and comprehensive translation and validation with a good sample size give a high impact for this study.

\section{CONCLUSION}

This study showed good psychometric properties and cultural adaptation of OKT-A tool and could be used in clinical setting or with Arabic general population. In addition, the results showed an urgent need for implementing an educational program to increase the knowledge toward OP and its related risk factor so that the preventing behaviour of the population can be improved.

\section{ETHICS APPROVAL AND CONSENT TO PARTI- CIPATE}

The study protocol was approved by the Scientific Committee of Al-Rafidain University Collage, Baghdad, Iraq.

\section{HUMAN AND ANIMAL RIGHTS}

No experiments involving human or animals were used in this research. This research was conducted in compliance with the principles laid in declaration of Helsinki in 1975 and revised in 1983.

\section{CONSENT FOR PUBLICATION}

All participants were provided with a written informed consent form prior to participation in this study. All personal information collected was considered confidential.

\section{CONFLICT OF INTEREST}

The authors declare no conflict of interest, financial or otherwise.

\section{ACKNOWLEDGEMENTS}

Declared none.

\section{REFERENCES}

[1] Azizieh FY. Fractures in Kuwait: Incidence and distribution. Risk Manag Healthc Policy 2017; 10: 117-25.

[http://dx.doi.org/10.2147/RMHP.S136844] [PMID: 28652834]

[2] Cosman F, de Beur SJ, LeBoff MS, et al. Clinician's guide to prevention and treatment of osteoporosis. Osteoporos Int 2014; 25(10): 2359-81.

[http://dx.doi.org/10.1007/s00198-014-2794-2] [PMID: 25182228]

[3] Hadjidakis DJ, Mylonakis AM, Sfakianakis ME, Raptis AE, Raptis SA. Diabetes and premature menopause: Is their co-existence detrimental to the skeleton? Eur J Endocrinol 2005; 152(3): 437-42. [http://dx.doi.org/10.1530/eje.1.01853] [PMID: 15757861]

[4] Mauck KF, Clarke BL. Diagnosis, screening, prevention, and treatment of osteoporosis. Mayo Clin Proc 2006; 81(5): 662-72. [http://dx.doi.org/10.4065/81.5.662] [PMID: 16706264]

[5] Seeman E, Delmas PD, Hanley DA, et al. Microarchitectural deterioration of cortical and trabecular bone: differing effects of denosumab and alendronate. J Bone Miner Res 2010; 25(8): 1886-94. [http://dx.doi.org/10.1002/jbmr.81] [PMID: 20222106]

[6] Abdulameer SA, Sahib MN, Sulaiman SAS. The prevalence of osteopenia and osteoporosis among malaysian type 2 diabetic patients using quantitative ultrasound densitometer. Open Rheumatol J 2018; 12: 50-64.

[http://dx.doi.org/10.2174/1874312901812010050] [PMID: 29755605]

[7] Tung WC, Lee IF. Effects of an osteoporosis educational programme for men. J Adv Nurs 2006; 56(1): 26-34.

[http://dx.doi.org/10.1111/j.1365-2648.2006.03976.x] [PMID: 16972 915]

[8] Watts NB, Lewiecki EM, Miller PD, Baim S. National osteoporosis foundation 2008 clinician's guide to prevention and treatment of osteoporosis and the World Health Organization fracture risk assessment tool (FRAX): what they mean to the bone densitometrist and bone technologist. J Clin Densitom 2008; 11(4): 473-7.

[http://dx.doi.org/10.1016/j.jocd.2008.04.003] [PMID: 18562228]

[9] Piaseu N, Belza B, Mitchell P. Testing the effectiveness of an osteoporosis educational program for nursing students in Thailand. Arthritis Rheum 2001; 45(3): 246-51.

[http://dx.doi.org/10.1002/1529-0131(200106)45:3<246:AID-ART256 >3.0.CO;2-Y] [PMID: 11409665]

[10] Siris ES, Chen Y-T, Abbott TA, et al. Bone mineral density thresholds for pharmacological intervention to prevent fractures. Arch Intern Med 2004; 164(10): 1108-12.

[http://dx.doi.org/10.1001/archinte.164.10.1108] [PMID: 15159268]

[11] Uusi-Rasi K, Sievänen H, Pasanen M, Oja P, Vuori I. Association of physical activity and calcium intake with the maintenance of bone mass in premenopausal women. Osteoporos Int 2002; 13(3): 211-7. [http://dx.doi.org/10.1007/s001980200016] [PMID: 11991440]

[12] Ford MA, Bass M, Zhao Y, Bai J-B, Zhao Y. Osteoporosis knowledge, self-efficacy, and beliefs among college students in the USA and China. J Osteoporos 2011; 2011: 729219.

[http://dx.doi.org/10.4061/2011/729219] [PMID: 21603144]

[13] Kasper MJ, Peterson MG, Allegrante JP. The need for comprehensive educational osteoporosis prevention programs for young women: results from a second osteoporosis prevention survey. Arthritis Rheum 2001; 45(1): 28-34.

[http://dx.doi.org/10.1002/1529-0131(200102)45:1<28::AID-ANR80> 3.0.CO;2-G] [PMID: 11308058]

[14] McLeod KM, Johnson CS. A systematic review of osteoporosis health beliefs in adult men and women. J Osteoporos 2011; 2011: 197454. [http://dx.doi.org/10.4061/2011/197454] [PMID: 21941678]

[15] Ozturk A, Sendir M. Evaluation of knowledge of osteoporosis and self-efficacy perception of female orthopaedic patients in Turkey. J Nurs Healthc Chronic Illn 2011; 3: 319-28. [http://dx.doi.org/10.1111/j.1752-9824.2011.01106.x]

[16] Patel A, Coates PS, Nelson JB, Trump DL, Resnick NM, Greenspan SL. Does bone mineral density and knowledge influence health-related behaviors of elderly men at risk for osteoporosis? J Clin Densitom 2003; 6(4): 323-30.

[http://dx.doi.org/10.1385/JCD:6:4:323] [PMID: 14716044]

[17] Williams B, Cullen L, Barlow JH. "I never realised how little I knew!": a pilot study of osteoporosis knowledge, beliefs, and behaviours. Health Care Women Int 2002; 23(4): 344-50. [http://dx.doi.org/10.1080/0739933029008919] [PMID: 12148912]

[18] Werner P. Knowledge about osteoporosis: assessment, correlates and outcomes. Osteoporos Int 2005; 16(2): 115-27. [http://dx.doi.org/10.1007/s00198-004-1750-y] [PMID: 15517187] 
[19] Ishtaya GA, Anabtawi YM, Zyoud SH, Sweileh WM. Osteoporosis knowledge and beliefs in diabetic patients: a cross sectional study from Palestine. BMC Musculoskelet Disord 2018; 19(1): 43. [http://dx.doi.org/10.1186/s12891-018-1961-6] [PMID: 29415696]

[20] Sayed-Hassan R, Bashour H, Koudsi A. Osteoporosis knowledge and attitudes: A cross-sectional study among female nursing school students in Damascus. Arch Osteoporos 2013; 8: 149 [http://dx.doi.org/10.1007/s11657-013-0149-9] [PMID: 23999904]

[21] Sayed-Hassan RM, Bashour HN. The reliability of the Arabic version of Osteoporosis Knowledge Assessment Tool (OKAT) and the Osteoporosis Health Belief Scale (OHBS). BMC Res Notes 2013; 6: 138.

[http://dx.doi.org/10.1186/1756-0500-6-138] [PMID: 23566522]

[22] Sweileh WM, Al-Jabi SW, Zyoud SH, Sawalha AF, Ghanim MA. Osteoporosis is a neglected health priority in Arab World: A comparative bibliometric analysis. Springerplus 2014; 3: 427. [http://dx.doi.org/10.1186/2193-1801-3-427] [PMID: 25152852]

[23] Streiner DL, Norman GR, Cairney J. Health measurement scales: A practical guide to their development and use. USA: Oxford University Press 2015.

[http://dx.doi.org/10.1093/med/9780199685219.001.0001]

[24] Kim K, Horan M, Gendler P. Osteoporosis knowledge tests, osteoporosis health belief scale, and osteoporosis self-efficacy scale. Allendale, MI: Grand Valley State University 1991.

[25] Abdulameer SA, Syed Sulaiman SA, Hassali MA, Subramaniam K, Sahib MN. Psychometric properties of osteoporosis knowledge tool and self-management behaviours among Malaysian type 2 diabetic patients. J Community Health 2013; 38(1): 95-105.

[http://dx.doi.org/10.1007/s10900-012-9586-4] [PMID: 22772955]

[26] Beaton DE, Bombardier C, Guillemin F, Ferraz MB. Guidelines for the process of cross-cultural adaptation of self-report measures. Spine 2000; 25(24): 3186-91.

[http://dx.doi.org/10.1097/00007632-200012150-00014] [PMID: 1112 4735]

[27] Guillemin F, Bombardier C, Beaton D. Cross-cultural adaptation of health-related quality of life measures: Literature review and proposed guidelines. J Clin Epidemiol 1993; 46(12): 1417-32.

[http://dx.doi.org/10.1016/0895-4356(93)90142-N] [PMID: 8263569]

[28] Sahib MN. Validation and assessment of osteoporosis self-efficacy among iraqi general population. Open Nurs J 2018; 12: 76-85.

[http://dx.doi.org/10.2174/1874434601812010076] [PMID: 29997710]

[29] Wild D, Grove A, Martin M, et al. Principles of good practice for the translation and cultural adaptation process for Patient-Reported Outcomes (PRO) measures: Report of the ISPOR task force for translation and cultural adaptation. Value Health 2005; 8(2): 94-104. [http://dx.doi.org/10.1111/j.1524-4733.2005.04054.x] [PMID: 15804 318]

[30] Cronbach LJ. Coefficient alpha and the internal structure of tests. psychometrika 16: 297-334.1951;

[31] Sim SM, Rasiah RI. Relationship between item difficulty and discrimination indices in true/false-type multiple choice questions of a para-clinical multidisciplinary paper. Ann Acad Med Singapore 2006; 35(2): $67-71$ [PMID: 16565756]

[32] Ferguson GA. On the theory of test discrimination. psychometrika 1949; 14: 61-8.

[33] Baheiraei A, Ritchie JE, Eisman JA, Nguyen TV. Psychometric properties of the Persian version of the osteoporosis knowledge and health belief questionnaires. Maturitas 2005; 50(2): 134-9. [http://dx.doi.org/10.1016/j.maturitas.2004.05.001] [PMID: 15653011]

[34] Horan ML, Kim KK, Gendler P, Froman RD, Patel MD. Development and evaluation of the osteoporosis self-efficacy scale. Res Nurs Health 1998; 21(5): 395-403.

[http://dx.doi.org/10.1002/(SICI)1098-240X(199810)21:5<395::AIDNUR3>3.0.CO;2-I] [PMID: 9761137]

[35] Edmonds E, Turner LW, Usdan SL. Osteoporosis knowledge, beliefs, and calcium intake of college students: Utilization of the health belief model. Open J Prev Med 2012; 2: 27-34. [http://dx.doi.org/10.4236/ojpm.2012.21005]

[36] Lee LY, Lai EK. Osteoporosis in older Chinese men: Knowledge and health beliefs. J Clin Nurs 2006; 15(3): 353-5.

[http://dx.doi.org/10.1111/j.1365-2702.2006.01303.x] [PMID: 16466 485]

[37] Barzanji AT, Alamri FA, Mohamed AG. Osteoporosis: A study of knowledge, attitude and practice among adults in Riyadh, Saudi Arabia. J Community Health 2013; 38(6): 1098-105. [http://dx.doi.org/10.1007/s10900-013-9719-4] [PMID: 23780302]
[38] Anderson KD, Chad KE, Spink KS. Osteoporosis knowledge, beliefs, and practices among adolescent females. J Adolesc Health 2005; 36(4): 305-12.

[http://dx.doi.org/10.1016/j.jadohealth.2004.03.007] [PMID: 15780 785]

[39] Gemalmaz A, Oge A. Knowledge and awareness about osteoporosis and its related factors among rural Turkish women. Clin Rheumatol 2008; 27(6): 723-8.

[http://dx.doi.org/10.1007/s10067-007-0777-9] [PMID: 17965905]

[40] Nadler M, Alibhai S, Catton P, Catton C, To MJ, Jones JM. Osteoporosis knowledge, health beliefs, and healthy bone behaviours in patients on androgen-deprivation therapy (ADT) for prostate cancer. BJU Int 2013; 111(8): 1301-9.

[http://dx.doi.org/10.1111/j.1464-410X.2012.11777.x] [PMID: 23351 062]

[41] Terrio K, Auld GW. Osteoporosis knowledge, calcium intake, and weight-bearing physical activity in three age groups of women. J Community Health 2002; 27(5): 307-20.

[http://dx.doi.org/10.1023/A:1019840709367] [PMID: 12238730]

[42] Ribeiro V, Blakeley J, Laryea M. Women's knowledge and practices regarding the prevention and treatment of osteoporosis. Health Care Women Int 2000; 21(4): 347-53.

[http://dx.doi.org/10.1080/073993300245195] [PMID: 11813780]

[43] Taylor JC, Sterkel B, Utley M, et al. Opinions and experiences in general practice on osteoporosis prevention, diagnosis and management. Osteoporos Int 2001; 12(10): 844-8.

[http://dx.doi.org/10.1007/s001980170035] [PMID: 11716187]

[44] Abdulameer SA. A cross-sectional pilot study to investigate diabetic knowledge and pharmaceutical care practice among registered and unregistered pharmacists in Iraq. J Appl Pharm Sci 2018; 8: 113-21. [http://dx.doi.org/10.7324/JAPS.2018.81015]

[45] Abdulameer SA. Knowledge and pharmaceutical care practice regarding inhaled therapy among registered and unregistered pharmacists: An urgent need for a patient-oriented health care educational program in Iraq. Int J Chron Obstruct Pulmon Dis 2018; 13: 879-88.

[http://dx.doi.org/10.2147/COPD.S157403] [PMID: 29559772]

[46] Awad A, Waheedi M. Community Pharmacists role in obesity treatment in Kuwait: A cross-sectional study. BMC Public Health 2012; $12: 863$.

[http://dx.doi.org/10.1186/1471-2458-12-863] [PMID: 23057422]

[47] Drozdzowska B, Pluskiewicz W, Skiba M. Knowledge about osteoporosis in a cohort of Polish females: the influence of age, level of education and personal experiences. Osteoporos Int 2004; 15(8): 645-8.

[http://dx.doi.org/10.1007/s00198-003-1581-2] [PMID: 14735301]

[48] Kutsal YG, Atalay A, Arslan S, et al. Awareness of osteoporotic patients. Osteoporos Int 2005; 16(2): 128-33.

[http://dx.doi.org/10.1007/s00198-004-1678-2] [PMID: 15197545]

[49] Majumdar SR, Rowe BH, Folk D, et al. A controlled trial to increase detection and treatment of osteoporosis in older patients with a wrist fracture. Ann Intern Med 2004; 141(5): 366-73.

[http://dx.doi.org/10.7326/0003-4819-141-5-200409070-00011] [PMID: 15353428]

[50] Abdulameer SA, Syed Sulaiman SA, Hassali MA, Sahib MN, Subramaniam K. Psychometric properties of the Malay version of the Osteoporosis Health Belief Scale (OHBS-M) among Type 2 diabetic patients. Int J Rheum Dis 2014; 17(1): 93-105. [http://dx.doi.org/10.1111/1756-185X.12104] [PMID: 24472272]

[51] Sahib MN. Psychometric properties and assessment of the Osteoporosis Health Belief Scale among the general Arabic population. Patient Prefer Adherence 2018; 12: 223-32. [http://dx.doi.org/10.2147/PPA.S155152] [PMID: 29440877]

[52] Abdulameer SA, Syed Sulaiman SA, Hassali MA, Subramaniam K, Sahib MN. Psychometric properties and osteoprotective behaviors among type 2 diabetic patients: Osteoporosis self-efficacy scale Malay version (OSES-M). Osteoporos Int 2013; 24(3): 929-40. [http://dx.doi.org/10.1007/s00198-012-2071-1] [PMID: 22790611]

[53] Doheny MO, Sedlak CA, Estok PJ, Zeller RA. Bone density, health beliefs, and osteoporosis preventing behaviors in men. Orthop Nurs 2011;30(4): 266-72.

[http://dx.doi.org/10.1097/NOR.0b013e3182247a84] [PMID: 21799 384]

[54] Gammage KL, Francoeur C, Mack DE, Klentrou P. Osteoporosis health beliefs and knowledge in college students: the role of dietary restraint. Eat Behav 2009; 10(1): 65-7.

[http://dx.doi.org/10.1016/j.eatbeh.2008.10.006] [PMID: 19171323] 
[55] Ailinger RL, Emerson J. Women's knowledge of osteoporosis. Appl Nurs Res 1998; 11(3): 111-4.

[http://dx.doi.org/10.1016/S0897-1897(98)80102-X] [PMID: 9757 610]
[56] Sedlak CA, Doheny MO, Jones SL. Osteoporosis education programs: changing knowledge and behaviors. Public Health Nurs 2000; 17(5): 398-402.

[http://dx.doi.org/10.1046/j.1525-1446.2000.00398.x] [PMID: 11013 003]

(C) 2019 Abdulameer and Sahib

This is an open access article distributed under the terms of the Creative Commons Attribution 4.0 International Public License (CC-BY 4.0), a copy of which is available at: (https://creativecommons.org/licenses/by/4.0/legalcode). This license permits unrestricted use, distribution, and reproduction in any medium, provided the original author and source are credited. 